\title{
Diffussion of Thermo Effects on Unsteady Flow through Porous Medium
}

\author{
K. RamaPrasasd ,Ch. Baby Rani
}

\begin{abstract}
The intention of this research is to research the impact of thermo physiological parameters at the porous medium. The hallway present, heat radiation and source absorption effects have been into account. The expressions for the speed, temperature, and also the immersion field are derived by employing perturbation technique.
\end{abstract}

Keywords: Radiation absorption, Heat source, Iinclined porous plate, Heat transfer

\section{INTRODUCTION}

Radiation in free convection has also been studied by many authors because of its applications in many engineering and industrial processes.

"Dharmaiah and veeraKrishna [1] studied finite difference analysis on mhd free convection flow through a porous medium along a vertical wall. Veerakrishna and dharmaiah [2] analyzed mhd flow of a rivlin-ericson fluid through a porous medium in a parallel plate channel under externally applied boundary acceleration.in [2],[3],[4]. Dharmaiah performed effects of radiation, chemical reaction and soret on unsteady and Ramprasad et al., reported unsteady mhd convective heat and mass transfer flow past an inclined moving surface with heat absorption in [5],[6],[7].Analyzed chemical response, radiation and also dufour consequences on casson magneto hydro dynamics fluid flow on a vertical plate using Heating source/sink [8],[9],[10]over a vertical permeable plate Dharmaiah studied An unsteady magnetohydro lively heat transport flow in a rotating parallel plate station via a solid medium with radiation influence in [11],[12],[13],[14],[15].

Balamurugan et al., numerically analyzed effect of radiation absorption, viscous and joules dissipation on mhd complimentary convection chemically reactive and radiative stream at a moving likely porous plate using temperature dependent heat supply in[16],[17],[18],[19].

\section{MATHEMATICALT FORMULATION}

"In the Cartesian coordinate system, the $x^{\prime}$-is direction of the flow and the $y^{\prime}-$ axis normal to it. A normal magnetic field is assumed to be applied in the $y^{\prime}-$

direction",

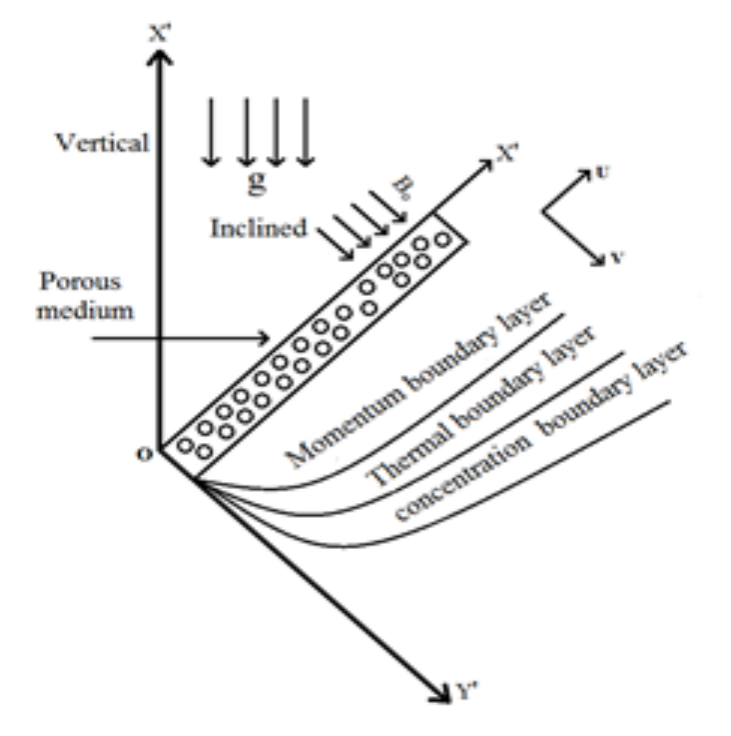

Figure 1: Geometry of the problem 
The governing equations are: “

$$
\begin{gathered}
\frac{\partial v^{\prime}}{\partial y^{\prime}}=0 \\
\frac{\partial u^{\prime}}{\partial t^{\prime}}+v^{\prime} \frac{\partial u^{\prime}}{\partial y^{\prime}}=v \frac{\partial^{2} u^{\prime}}{\partial y^{\prime 2}}+g \beta\left(T^{\prime}-T_{\infty}^{\prime}\right) \cos \alpha+g \beta^{*}\left(C^{\prime}-C_{\infty}^{\prime}\right) \cos \alpha-\frac{m}{1+m^{2}} \frac{\sigma B_{0}^{2}}{\rho} u^{\prime}-\frac{v}{k^{\prime}} u^{\prime} \\
\frac{\partial T^{\prime}}{\partial t^{\prime}}+v^{\prime} \frac{\partial T^{\prime}}{\partial y^{\prime}}=\frac{k}{\rho c_{p}} \frac{\partial^{2} T^{\prime}}{\partial y^{\prime 2}}+\frac{D_{m} k_{T}}{C_{S} c_{p}} \frac{\partial^{2} C^{\prime}}{\partial y^{\prime 2}}-\frac{Q_{0}^{\prime}}{\rho C p}\left(T^{\prime}-T_{\infty}^{\prime}\right)+Q_{1}^{\prime}\left(C^{\prime}-C_{\infty}^{\prime}\right) \\
\frac{\partial C^{\prime}}{\partial t^{\prime}}+v^{\prime} \frac{\partial C^{\prime}}{\partial y^{\prime}}=D \frac{\partial^{2} C^{\prime}}{\partial y^{\prime 2}}-K_{r}^{\prime}\left(C^{\prime}-C_{\infty}^{\prime}\right)
\end{gathered}
$$

The boundary conditions for the velocity, temperature, and concentration fields are given as follows:

$$
\begin{array}{lrlrl}
u^{\prime} & =0, T^{\prime}=T_{w}^{\prime}+\varepsilon\left(T_{w}^{\prime}-T_{\infty}^{\prime}\right) e^{\eta^{\prime} t^{\prime}}, C^{\prime}=C_{w}^{\prime}+\varepsilon\left(C_{w}^{\prime}-C_{\infty}^{\prime}\right) e^{\eta^{\prime} t^{\prime}} & \text { at } \quad y^{\prime}=0 \\
u^{\prime}=0, & T^{\prime} \rightarrow T_{\infty}^{\prime}, & C^{\prime} \rightarrow C_{\infty}^{\prime} & \text { as } \quad y^{\prime} \rightarrow \infty
\end{array}
$$

Where

$T_{w}^{\prime}$ and $C_{w}^{\prime}$ are the temperature and concentration near the plate respectively and $\eta^{\prime}$ is the constant. Thus, assuming the suction velocity to be oscillatory about a non-zero constant mean, one can write $v^{\prime}=-v_{0}\left(1+\varepsilon e^{i \eta^{\prime} t^{\prime}}\right)$,

The following non-dimensional quantities are: “

$$
\begin{aligned}
& y=\frac{v_{0} y^{\prime}}{4 v}, u=\frac{u^{\prime}}{v_{0}}, t=\frac{t^{\prime} v_{0}^{2}}{4 v}, \theta=\frac{T^{\prime}-T_{\infty}^{\prime}}{T_{w}^{\prime}-T_{\infty}^{\prime}}, C=\frac{C^{\prime}-C_{\infty}^{\prime}}{C_{w}^{\prime}-C_{\infty}^{\prime}}, K=\frac{K^{\prime} v_{0}^{2}}{v^{2}}, \\
& G r=\frac{g \beta v\left(T_{w}^{\prime}-T_{\infty}^{\prime}\right)}{v_{0}^{3}}, \operatorname{Pr}=\frac{v \rho C_{p}}{k}, K_{r}=\frac{K_{r}^{\prime} v}{v_{0}^{2}}, G m=\frac{g \beta^{*} v\left(C_{w}^{\prime}-C_{\infty}^{\prime}\right)}{v_{0}^{3}}, \\
& S c=\frac{v}{D}, \eta=\frac{4 v \eta^{\prime}}{v_{0}^{2}}, M=\frac{\sigma B_{0}^{2} v}{\rho v_{0}^{2}}, D_{u}=\frac{D\left(C_{w}^{\prime}-C_{\infty}^{\prime}\right)}{v\left(T_{w}^{\prime}-T_{\infty}^{\prime}\right)}, Q^{\prime}{ }_{0}=\frac{Q_{h} K v_{0}^{2}}{v^{2}}, \\
& Q_{1}^{\prime}=\frac{\left(T_{w}^{\prime}-T_{\infty}^{\prime}\right) v_{0}^{2} Q_{a}}{\left(C_{w}^{\prime}-C_{\infty}^{\prime}\right) v}
\end{aligned}
$$

The governing equations are

$$
\begin{aligned}
& \frac{1}{4} \frac{\partial u}{\partial t}-\left(1+\varepsilon e^{i \eta t}\right) \frac{\partial u}{\partial y}=I_{r} \theta+I_{m} C+\frac{\partial^{2} u}{\partial y^{2}}-H u \\
& \frac{1}{4} \frac{\partial \theta}{\partial t}-\left(1+\varepsilon e^{i \eta t}\right) \frac{\partial \theta}{\partial y}=\frac{1}{\operatorname{Pr}} \frac{\partial^{2} \theta}{\partial y^{2}}+D_{u} \frac{\partial^{2} C}{\partial y^{2}}-\frac{1}{\operatorname{Pr}} \theta Q_{h}+Q_{a} C \\
& \frac{1}{4} \frac{\partial C}{\partial t}-\left(1+\varepsilon e^{i \eta t}\right) \frac{\partial C}{\partial y}=\frac{1}{S c} \frac{\partial^{2} C}{\partial y^{2}}-K_{r} C
\end{aligned}
$$

Where

$$
I_{r}=G r \cos \alpha, I_{m}=G m \cos \alpha, H=\left(\frac{m}{1+m^{2}} M+\frac{1}{K}\right)
$$

The boundary conditions are transformed to:

$$
\begin{aligned}
& u=0, \theta=1+\varepsilon e^{i \eta t}, \quad C=1+\varepsilon e^{i \eta t} \quad \text { at } \quad y=0 \\
& u \rightarrow 0, \quad \theta \rightarrow 0, \quad C \rightarrow 0 \quad \text { as } \quad \mathrm{y} \rightarrow \infty
\end{aligned}
$$




\section{SOLUTION OF THE PROBLEM}

The following equations can be solved analytically. The representation of the velocity, temperature and concentration are "

$$
\begin{aligned}
& u(y, t)=u_{0}(y)+\varepsilon e^{i \eta t} u_{1}(y)+o\left(\varepsilon^{2}\right)+\ldots \\
& \theta(y, t)=\theta_{0}(y)+\varepsilon e^{i \eta t} \theta_{1}(y)+o\left(\varepsilon^{2}\right)+\ldots \\
& C(y, t)=C_{0}(y)+\varepsilon e^{i \eta t} C_{1}(y)+o\left(\varepsilon^{2}\right)+
\end{aligned}
$$

Substituting (11) in Eqs (7) - (9P) and equating the harmonic and non - harmonic terms

$$
\begin{gathered}
\text { we get } \\
u_{0}^{\prime \prime}+u_{0}^{\prime}-H u_{0}=-I_{r} \theta_{0}-I_{m} C_{0} \\
u_{1}^{\prime \prime}+u_{1}^{\prime}-F_{2} u_{1}=-I_{r} \theta_{1}-I_{m} C_{1}-u_{0}^{\prime} \\
\theta_{0}^{\prime \prime}+\operatorname{Pr} \theta_{0}^{\prime}-Q_{h} \theta_{0}=-\operatorname{Pr} D_{u} C_{0}^{\prime \prime}-\operatorname{Pr} Q_{a} C_{0}
\end{gathered}
$$

$$
\theta_{1}^{\prime \prime}+\operatorname{Pr} \theta_{1}^{\prime}-F_{1} \theta_{1}=-\operatorname{Pr} \theta_{0}^{\prime}-\operatorname{Pr} D_{u} C_{1}^{\prime \prime}-\operatorname{Pr} Q_{a} C_{1}
$$

$$
\begin{gathered}
C_{0}^{\prime \prime}+S c C_{0}^{\prime}-S c K_{r} C_{0}=0 \\
C_{1}^{\prime \prime}+S c C_{1}^{\prime}-S c\left(K_{r}+\frac{i \eta}{4}\right) C_{1}=-C_{0}^{\prime}
\end{gathered}
$$

The corresponding boundary conditions are

$$
\begin{aligned}
& u_{0}=0, u_{1}=0, \theta_{0}=1, \theta_{1}=1, C_{0}=1, C_{1}=1 \quad \text { at } \quad y=0 \\
& u_{0} \rightarrow 0, u_{1} \rightarrow 0, \theta_{0} \rightarrow 0, \theta_{1} \rightarrow 0, C_{0} \rightarrow 0, C_{1} \rightarrow 0 \quad \text { as } y \rightarrow \infty
\end{aligned}
$$

Solving eq's (12) - (17) under the (18) we get theexpressions for velocity, temperature and concentration are

$$
\begin{array}{r}
u(y, t)=\left[A_{11} \exp \left(-m_{5} y\right)-A_{9} \exp \left(-m_{3} y\right)-A_{10} \exp \left(-m_{1} y\right)\right] \\
+\varepsilon \exp (i \eta t)\left[\begin{array}{l}
A_{17} \exp \left(-m_{6} y\right)+A_{12} \exp \left(-m_{5} y\right)-A_{13} \exp \left(-m_{4} y\right) \\
-A_{14} \exp \left(-m_{3} y\right)-A_{15} \exp \left(-m_{2} y\right)-A_{16} \exp \left(-m_{1} y\right)
\end{array}\right] \\
\theta(y, t)=\left[A_{4} \exp \left(-m_{3} y\right)+A_{3} \exp \left(-m_{1} y\right)\right]+\varepsilon \exp (i \eta t)\left[\begin{array}{l}
A_{8} \exp \left(-m_{4} y\right)+A_{5} \exp \left(-A_{3} y\right) \\
+A_{6} \exp \left(-m_{2} y\right)+A_{7} \exp \left(-m_{1} y\right)
\end{array}\right] \\
C(y, t)=\exp \left(-m_{1} y\right)+\varepsilon \exp (i \eta t)\left[A_{1} \exp \left(-m_{1} y\right)+A_{2} \exp \left(-m_{2} y\right)\right]
\end{array}
$$

The expressions forSkin-friction coefficient, the Nusselt number and the Sherwood number are

$$
\begin{gathered}
C_{f}=\left(\frac{\partial u}{\partial y}\right)_{y=0}=\left(m_{3} A_{9}+m_{1} A_{10}-m_{5} A_{11}\right)+\varepsilon \exp (i \eta t) \\
\left(-m_{6} A_{17}-m_{5} A_{12}+m_{4} A_{13}+m_{3} A_{14}+m_{2} A_{15}+m_{1} A_{16}\right) \\
N u=-\left(\frac{\partial \theta}{\partial y}\right)_{y=0}=\left(m_{3} A_{4}+m_{1} A_{3}\right)+\varepsilon \exp (i \eta t)\left(m_{4} A_{8}+m_{3} A_{5}+m_{2} A_{6}+m_{1} A_{7}\right) \\
S h=-\left(\frac{\partial C}{\partial y}\right)_{y=0}=m_{1}+\varepsilon \exp (i \eta t)\left(m_{2} A_{2}+m_{1} A_{1}\right) “
\end{gathered}
$$

\section{RESULTS AND DISCUSSION}

The present study is the effects of diffussion thermo effects on unsteady free convective two-dimensional flow past an infinite inclined plate act of placing in a porous medium The effects of followingvarious parameterson like $G r, G m, M, K, \operatorname{Pr}, S c, D_{u}, \mathrm{Q}_{\mathrm{h}}, \mathrm{Q}_{\mathrm{a}}, \alpha$ and $K_{r}$ on the $\mathrm{u}, \theta_{s}$ chave been studiedanalytically.

Figure.1: Effects of Schmidt number on velocity profiles

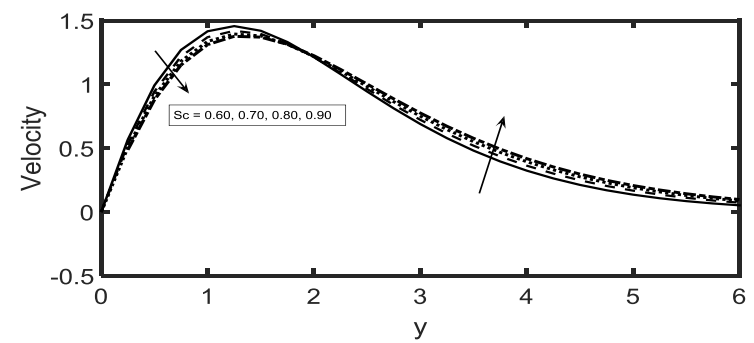

Figure 1 show sthat the velocity decreases with increasing Schmidt number until critical point after that it is increases. 4

Figure.2:Effects of inclined angled on velocity profiles 


\section{Diffussion of Thermo Effects on Unsteady Flow through Porous Medium}

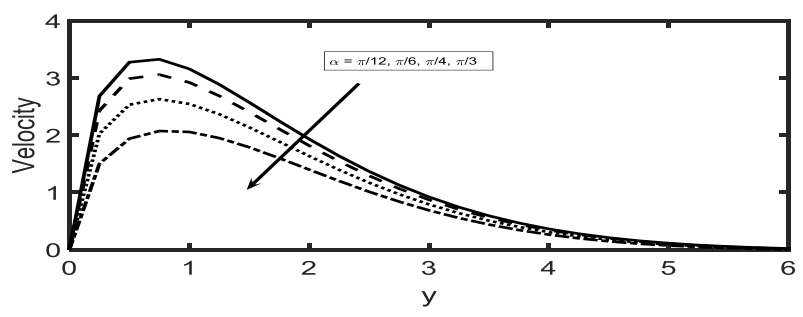

From figure 2it shows that boundary layer flow for the velocity decreases with the increase of the angle of inclination.

Figure.3: Effects of Heat Radiation on velocity profiles.

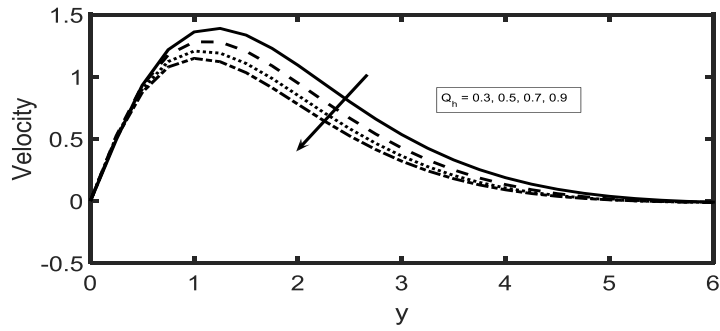

From figure 3, it is cleared that velocity decreases as the radiation parameter $\mathrm{Q}_{\mathrm{h}}$ increases.

Figure.4: Effects of Heat Absorption on velocity profiles.

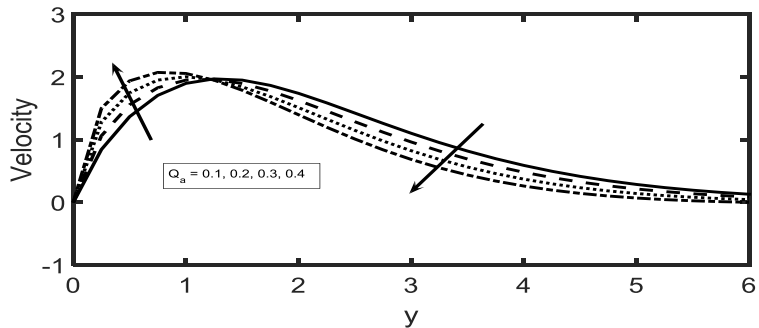

From figure 4it shows that, increase in Qa there is an increase in the velocity until critical point and afterwards it is decreases.

Figure5: Effects of Dufour parameter Du on temperature profiles

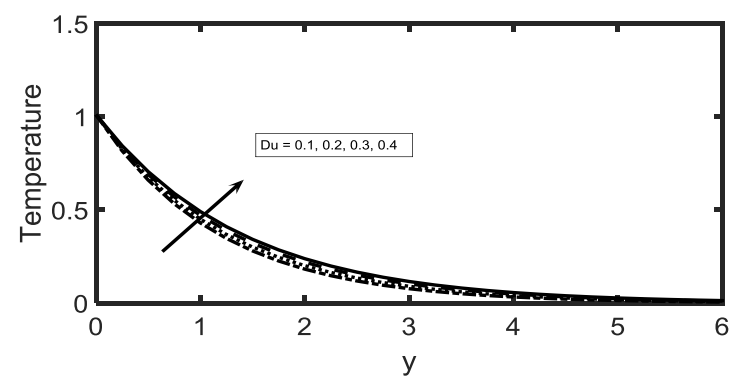

From figure 5 it showsthat the Dufour parameter increases, the fluid temperature distribution also increases.

Figure.6: Effects of Radiation Absorption $\mathrm{Q}_{\mathrm{a}}$ on temperature profiles.

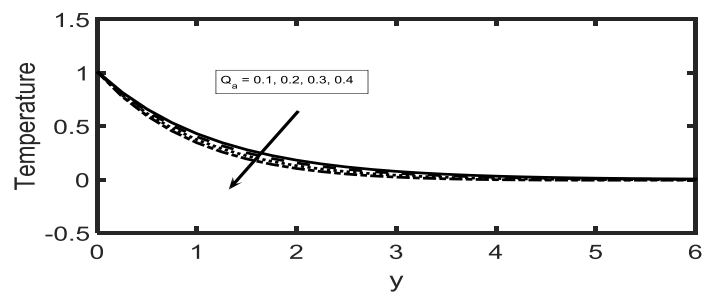

From figure 6, the effect of radiation absorption is found to decrease the temperature boundary layer.

Figure.7: Effects of Heat radiation parameter $\mathrm{Q}_{\mathrm{h}}$ on Nusselt number.

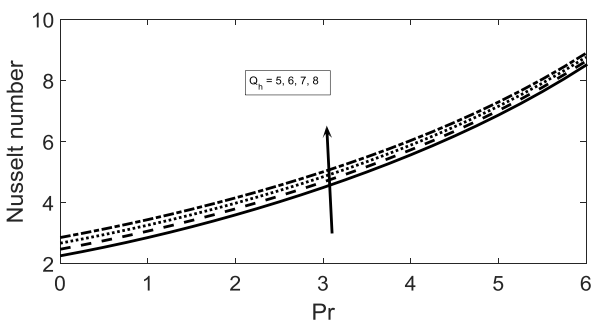

From figure 7 shows that Nusselt number inecreases as an increase in $\mathrm{Q}_{\mathrm{h}}$.

Figure.8: Effects of Schmidt number Sc on Sherwood number

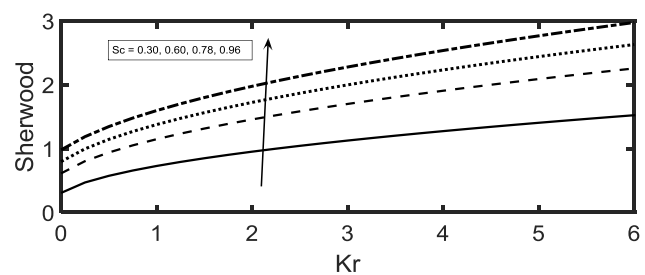

Fromfigure 8it showsthat Sherwood number inecreases as an increase in $\mathrm{Sc}$

\section{CONCLUSIONS:}

The present numerical study isthe effects of diffussion thermo physical parameters in a porous.

\section{REFERRENCES}

1. G.Dharmaiah, M. Veera Krishna, "Finite Difference Analysis on MHD Free Convection Flow Through A Porous Medium Along A Vertical Wall”, Asian Journal of Current Engineering and Maths 2: 4 July August (2013) p.p. $273-280$.

2. M. Veera Krishna and G. Dharmaiah, "MHD Flow of a Rivlin-Ericson Fluid through a Porous Medium in a Parallel Plate Channel under externally applied boundary acceleration", International Journal of Engineering Inventions, e-ISSN: 2278-7461, p-ISSN: 2319-6491, Volume 2, Issue 9 (May 2013) PP: 34-40.

3. M. Veera Krishna and G. Dharmaiah, "hall effects on MHD pulsatile flow through a porous medium in a flexible channel", International Journal of Advances in Engineering \& Technology, Sept. 2013.CIJAET ISSN: 22311963,vol-6,issue no:2,pp:1552-1563. 
4. M. veerakrishna and G. DHARMAIAH, "heat transfer on unsteady MHDcouette flow of a bingham fluid through a porous medium in a parallel plate channel with uniform suction and injection under the effect of inclined magnetic field and taking hall currents", IJAMA : Vol. 5, No. 2, December 2013, pp. 147-163 @ Global Research Publications

5. DharmaiahGurram, VedavathiNallapati, K.S.Balamurugan, "Effects Of Radiation, Chemical Reaction And Soret On Unsteady Mhd Free Convective Flow Over A Vertical Porous Plate", IJSIMR,Vol 3, special issue 5, Nov 2015, pp 93-101.

6. J.L.Ramprasad, K.S.Balamurugan, DharmaiahGurram, "Unsteady Mhd Convective Heat And Mass Transfer Flow Past An Inclined Moving Surface With Heat Absorption", JP Journal of Heat and Mass Transfer, Vol XIII, Issue-1,Nov 2016,pp 33-51.

7. Charan Kumar Reaction AndSoret Effects On CassonMhd Fluid Over A Vertical Plate", Int. J. Chem.Sci.: 14(1), 2016, 213-221.ISSN 0972-768X.

8. VedavatiNallapati, DharmaiahGurram, K.S.Balamurugan, Charan Kumar Gandeta "Chemical Reaction, Radiation And Dufour Effects On Casson Magneto Hydro Dynamics Fluid Flow Over A Vertical Plate With Heat Source /Sink", Global Journal Of Pure And Applied Mathematics, ISSN 0973-1768,Vol XII, No.1,2016,pp 191-200.

9. Ch.BabyRani,DharmaiahGurram,K.S.Balamurugan,Sk.Mohiddin Shaw, "Synthetic Response And Radiation Impacts On Unsteady MHD Free Convective Flow Over A Vertical Permeable Plate", Int. J. Chem.Sci.: 14(4), 2016, 2051-2065,ISSN 0972-76

10. K.S.Balamurugan, DharmaiahGurram, S.V.K.Varma, V.C.C.Raju, "MHD Free Convective Flow Past a Semi-Infinite Vertical Permeable Moving Plate with Heat Absorption", International Journal of Engineering \& Scientific Research, ISSN: 2347-6532, Vol IV, Issue 8, August 2016, p.p.46-58.

11. M.Venkateswarlu, D. Venkatalakshmi, G.Dharmaiah, "Influence Of Slip Condition On RadiativeMhd Flow Of A Viscous Fluid In Parallel Porous Plate Channel In Presence Of Heat Absorption And Chemical Reaction", J.KSIAM, vol-20, No-4, 2016, p.p:333-354.

12. G.Dharmaiah, "An Unsteady Magneto Hydro Dynamic Heat Transfer Flow In A Rotating Parallel Plate Channel Through A Porous Medium With Radiation Effect", Innovare Journal Of Engineering \& Technology,vol-5(1),2017,p.p:34-37.

13. G.Dharmaiah, UdayKumarY, N.Vedavathi, "Magneto Hydro Dynamics Convective Flow Past A Vertical Porous Surface In Slip-Flow Regime", IJTAM(RIP Publications), ISSN: 0973-6085, vol-12(1), pp:71-81,2017.

14. G.Dharmaiah, K.S.Balamurugan, V.C.C.Raju, N.Vedavathi, "effect of chemical reaction on mhdcasson fluid flow past an inclined surface with radiation", SKIT Journal, ISSN: 2278-2508, vol-7(1), pp:53-59.

15. Ch.BabyRani, K.Ramaprasad, K.S.Balamurugan, DharmaiahGurram, "MHD Transient Free Convection Aligned Magnetic and Chemically Reactive Flow past a Porous Inclined Plate with Radiation and Temperature Gradient Dependent Heat Source in Slip Flow Regime", IOSR Journal of Mathematics (IOSR-JM) e-ISSN: 2278-5728, p-ISSN 2319-765X. Volume 13, Issue 4 Ver. I (Jul. - Aug. 2017), PP 34-45.

16. DharmaiahGurram, Prakash.J, K.S.Balamurugan, N.Vedavathi, "The Effect Of Chemical Reaction On Heat And Mass Transfer Mhd Flow Ag, $\mathrm{Tio}_{2}$ And $\mathrm{Cu}$ Water Nano Fluids Over A Semi Infinite Surface", Global Journal Of Pure And Applied Mathematics, ISSN 0973-1768,Vol XIII, No.9,2017,pp 6609-6632.

17. K.S. Balamurugan, J.L. Ramaprasad, DharmaiahGurram and V.C.C. Raju, "Influence of Radiation Absorption, Viscous and Joules dissipation on MHD free Convection Chemically Reactive and Radiative Flow in a Moving Inclined Porous Plate with Temperature Dependent Heat Source", International Refereed Journal of Engineering and Science (IRJES), ISSN : 2319-183X, Volume 5, Issue 12 (December 2016), PP.20-31.

18. Ch.Baby Rani, Sk. Mohiddin Shaw, G.Dharmaiah, "Influence Of Radiation On Heat And Mass Transfer In MHD Fluid Flow Over An Infinite Vertical Porous Surface With Chemical Reaction", International Journal of Mathematics and its Applications, ISSN:2345-1557, Vol:5, Issuse 4-E, 2017, 731-740.

19. DharmaiahGurram, K.S.Balamurugan, M. Venkateswarulu, "Analysis Of Heat And Mass Transfer On Mhd Flow Of Nanofluid Over A Semi Infinite Moving Surface With Diffusion Thermo", SKIT Journal, volume-7, Issuse-2, 2017, ISSN: 2278-2508, 79-86. 